\title{
The changing structure of diets in the European Union in relation to healthy eating guidelines
}

\author{
Josef Schmidhuber ${ }^{1}$ and W Bruce Traill ${ }^{2, *}$ \\ ${ }^{1}$ Food and Agriculture Organization, Rome, Italy: ${ }^{2}$ Department of Agricultural and Food Economics, \\ The University of Reading, PO Box 237, Reading RG6 6AR, UK
}

Submitted 30 September 2004: Accepted 27 June 2005

\begin{abstract}
Objective: Our objective in this paper is to assess diets in the European Union (EU) in relation to the recommendations of the recent World Health Organization/Food and Agriculture Organization expert consultation and to show how diets have changed between 1961 and 2001.

Data and methods: Computations make use of FAOSTAT data on food availability at country level linked to a food composition database to convert foods to nutrients. We further explore the growing similarity of diets in the EU by making use of a consumption similarity index. The index provides a single number measure of dietary overlap between countries.

Results: The data confirm the excessive consumption by almost all countries of saturated fats, cholesterol and sugars, and the convergence of nutrient intakes across the EU. Whereas in 1961 diets in several European countries were more similar to US diets than to those of other European countries, this is no longer the case; moreover, while EU diets have become more homogeneous, the EU as a whole and the USA have become less similar over time.

Conclusions: Although the dominant cause of greater similarity in EU diets over the period studied is increased intakes in Mediterranean countries of saturated fats, cholesterol and sugar, also important are reductions in saturated fat and sugar in some Northern European countries. This suggests that healthy eating messages are finally having an impact on diets; a distinctly European diet may also be emerging.
\end{abstract}

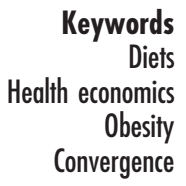

Amidst growing global concern about obesity and its consequences, notably diabetes, cardiovascular disease and cancer, consumers are being exhorted to eat less, exercise more and change the composition of their diets away from animal products rich in saturated fats towards fruit and vegetables (low in saturated fats, high in micronutrients such as antioxidants and flavonoids), seafood and whole-grain cereals. The so-called Mediterranean diet, essentially the diet of Greek peasant farmers in the 1950s, is held to represent an ideal. Meanwhile, consumers in the European Union (EU) and elsewhere spend their growing incomes on meat, alcohol and convenience processed foods whilst working and enjoying leisure activities that are less physically demanding than the lifestyles of earlier generations. Food and health policy-makers face calls for better labelling of food, education (including the teaching of cooking skills in schools and more physical education in schools), controls on food advertising, private-sector advertising to be counterbalanced by enhanced pro-healthy eating campaigns, and for the use of taxes and subsidies to manipulate relative prices in favour of healthy eating (a theme encapsulated within the recurrent demands for a 'fat tax'). Food manufacturers, retailers and the food service industry face calls to reduce the fat, salt and sugar contents of processed foods and to make portion sizes smaller.

Against this background, the World Health Organization (WHO) and the Food and Agriculture Organization of the United Nations (FAO) set up an expert consultation on Diet, Nutrition and the Prevention of Chronic Diseases that reported in $2003^{1}$. Population recommendations from the expert consultation are shown in Table 1 . The report pays considerable attention to the importance of a balanced diet and its ability to prevent chronic diseases.

The International Obesity Task Force (IOTF) and the European Association for the Study of Obesity (EASO) have collected data showing that in many European countries more than half of all adults are overweight and up to $30 \%$ are clinically obese ${ }^{2}$. As a generalisation, the data from the IOTF suggest that men are more likely to be overweight but women are more likely to be obese. 
Table 1 Ranges of population nutrient intake goals

\begin{tabular}{ll}
\hline Dietary factor & $\begin{array}{c}\text { Recommended dietary intake ranges } \\
\text { (as a share of total energy intake) }\end{array}$ \\
\hline Total fat & $15-30 \%$ \\
Polyunsaturated fatty acids & $6-10 \%$ \\
Saturated fatty acids & $<10 \%$ \\
Trans fatty acids & $<1 \%$ \\
Total carbohydrate* & $55-75 \%$ \\
Free sugars† & $<10 \%$ \\
Protein & $10-15 \%$ \\
Cholesterol & $<300 \mathrm{mg}$ \\
Sodium chloride (sodium) & $<5 \mathrm{~g}(<2 \mathrm{~g})$ \\
Fruit and vegetables & $>400 \mathrm{~g}$ \\
Total dietary fibre/non-starch polysaccharides & $>25 \mathrm{~g} / 20 \mathrm{~g}$ from whole-grain \\
& cereals, fruit and vegetables
\end{tabular}

Source: Adapted from the World Health Organization (WHO)/Food and Agriculture Organization (FAO) report Diet, Nutrition and The Prevention of Chronic Diseases ${ }^{1}$, Table 6, p. 56.

* Percentage of total energy available after taking into account that consumed as protein and fat; hence the wide range.

†The term 'free sugars' refers to all monosaccharides and disaccharides added to foods by the manufacturer, cook or consumer, plus sugars naturally present in honey, syrups and fruit juices.

$\ddagger$ The suggested range should be seen in the light of the Joint WHO/FAO/United Nations University Expert Consultation on Protein and Amino Acid Requirements in Human Nutrition, held in Geneva, 9-16 April 2002.

We conclude that the relationships between diet and health are of crucial social and economic significance*. There is an urgent need in the social sciences for research into the determinants of nutrient intake - most existing research has studied the demand for foods in the context of markets, marketing or food safetyt. In contrast, policy-makers concerned with health promotion need to know how their decisions affect overall diets. Our goals in this paper are more modest, but an important first step: we take stock of EU dietsł and how they are changing in relation to $\mathrm{WHO} / \mathrm{FAO}$ guidelines. Such information is relevant to policy-makers setting priorities for allocating resources to specific aspects of diet change. Particularly when presented in a crosscountry context and over time, this analysis shows how one country is performing relative to others with respect to specific nutrients and indicates the extent to which dietary adjustment is achievable (if it has been achieved elsewhere - e.g. reductions in saturated fat intake in some Northern European countries). Of course, our analysis does not tell how such changes can be achieved.

*Some estimates quoted in the IOTF/EASO study ${ }^{2}$ suggest direct costs of obesity in the USA to be $\$ 70$ billion, representing $7 \%$ of health expenditure. In the UK, direct costs were estimated at $€ 816$ million, with indirect costs a further $€ 3.3$ billion. Various studies ${ }^{3,4}$ show that the economic costs of obesity in developed countries far outweigh the costs associated with food safety, yet the latter seems to have caused more alarm to the general public (e.g. bovine spongiform encephalopathy).

†Examples include Grigg ${ }^{5}$, Gil et al. ${ }^{6}$, Tiffin and Tiffin ${ }^{7}$, Mazzocchi ${ }^{8}$ and Lusk et al. ${ }^{9}$. Notable recent exceptions are Huang ${ }^{10}$ and Chen et al. ${ }^{11}$.

¥Note that FAOSTAT combines Belgium and Luxembourg; the analysis therefore refers to those countries combined plus Austria, Denmark, Finland, France, Germany, Greece, Ireland, Italy, The Netherlands, Portugal, Spain, Sweden and the UK.
After discussing the strengths and weaknesses of our data in the following section, the paper proceeds to assess availability at country level of the major nutrients for which WHO/FAO made recommendations in its consultation. We note convergence at this level, with extremes in high and low availability across countries diminishing over time. In the subsequent section we therefore proceed to quantify this convergence in an overall index, the consumption similarity index (CSI).

\section{How do EU diets match the recommendations?}

\section{The database, its strengths and weaknesses}

The most comprehensive and widely comparable database used to assess diets internationally comprises the FAO's Food Balance Sheets (FBS)*. The FBS are part of the FAO's overall FAOSTAT database, and are compiled from a highly disaggregated set of supply-utilisation accounts (SUA)t. The FBS provide the most comprehensive measure of food availability at country level, covering all food items consumed in a given country, regardless of the location of consumption (household or outside the home). Here we combine FAOSTAT data on food availability at country level with relevant nutrient information from food composition tables. The only comprehensive source for these food composition data is the US National Nutrient Database ${ }^{13}$, which has been used

*The DAFNE (DAta Food NEtworking) initiative has made substantial progress in bringing together household budget survey data in European countries and could become a useful tool for analysing nutrient intakes in Europe, including assessment of at-risk groups ${ }^{12}$. †For the analysis presented in this paper, the most detailed commodity breakdown of the SUA was used which distinguished more than 420 individual food items. At this level of disaggregation, the database is however not available publicly. 
extensively for this analysis. Together these databases provide a complete picture not only of food but also of nutrient availability.

However, there are also problems associated with the use of the FBS for dietary assessments. Most importantly, the FBS suffer from the problem that plagues all supply-based food assessment systems: that the food consumption estimates reflect information on food availability at country level rather than actual intake at household or individual level. Food availability is essentially derived from a commodity balance, i.e. from production adjusted for trade, industrial usage, stock changes, feed use, processing and an estimate of postharvest losses*. The data therefore represent 'apparent' consumption at the retail level rather than actual consumption at the household or individual level.

The exclusion of all losses that can occur after the retail level can result in a considerable overestimation of actual food intake. There is no comprehensive overview as to how significant these losses are across countriest, although, in general, losses are thought to be positively correlated to the overall level of dietary energy supply (DES) and are therefore higher in developed than in developing countries. Neither is there a comprehensive overview as to how losses differ across commodities, although empirical estimates based on US household analysis suggest that there are considerable differences in the level of losses across the commodity spectrum (see Fig. $1^{15}$ ). In terms of energy lost, fats and oils represent the most important rubric for potential overestimation of food intake. These losses occur when fat is trimmed off the meat or when cooking and frying oil is discarded rather than consumed. In terms of quantity, it is estimated that the largest losses occur for perishable products like fresh fruits and vegetables. Regardless of these country and commodity specificities, it is clear that post-retail losses can introduce a considerable 'wedge' between availability and actual intake.

In principle, the discrepancy between availability and actual intake could pose a considerable problem for evaluation of the composition of individual diets against the proposed dietary guidelines. There is, however, a crucial fact that mitigates the impact of unaccounted waste considerably. Dietary guidelines are in general expressed in relative terms (relative to the DES), which means that the possible error made is limited to errors that occur when losses are not uniformly distributed across different food items.

*Food supply in the FAO FBS is defined as availability at the retail level. It has been corrected for post-harvest and processing losses but still includes all forms of 'post-retail' losses, notably household waste, retailing losses and pet food.

tA notable exception is the USA. Putnam et al. ${ }^{14}$ suggest that the difference between food available for consumption and food supply after adjustments for spoilage, cooking losses, plate waste and other losses has reached a level of more than one-quarter of the DES, or slightly more than $1000 \mathrm{kcal}_{\text {person }}{ }^{-1} \mathrm{day}^{-1}$.

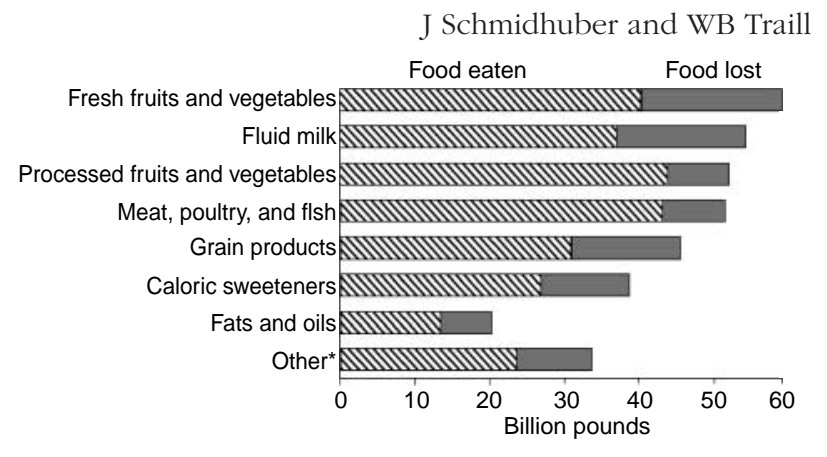

Fig. 1 The importance of food losses by commodity, USA. The largest losses were in the fresh fruits and vegetables, fluid milk and grain products sectors in 1995. *Other includes eggs, peanuts, tree nuts, dry beans, peas and lentils, and dairy products other than fluid milk. Source: Kantor et al. ${ }^{15}$

Another obvious problem of using country-level data is that we can only acquire information on population averages; we are unable to analyse population subgroups that might be of particular interest - at-risk groups such as children, the elderly or those from disadvantaged backgrounds.

Finally, we must recognise the approximations involved in using a US food composition database in a European context, although the discrepancies in composition between Europe and the USA may be much smaller than if applying the approach in a developing country context.

With all of these caveats in mind, the next step was to create a nutrient database for all EU member countries. The principal approach was to 'match-merge' all individual food items of the SUA with the same food items of food composition tables, and thus convert data on food availability by country into their respective nutrients (protein, fatty acids, cholesterol, etc.). The individual nutrient data were then added up over all food items to obtain the total nutrient availability levels of the complete diet. In fact, this process was applied across all countries, years and elements of the SUA (production, trade, stock changes, etc.), providing a complete nutrient balance for each country and year (1961 to 2001).

\section{Overview of the results}

To obtain a first general overview of the dietary situation in the EU, a headcount of countries was created with the number of countries below and above the most important recommendations. The time span is 1961 to 2001, which makes it possible to trace how the availability of individual dietary components has changed over the past 40 years relative to the recommended intake levels.

Without trying to interpret the results in detail, the figures presented in Table 2 reveal that there have been both improvements and deteriorations in nutrient supplies relative to the recommendations. The number of countries that reached and exceeded the limit of 400 g person $^{-1}$ day $^{-1}$ for fruit and vegetable supply, for instance, has increased steadily over the last 40 years from only six in the early 1960 s 
Table 2 How many countries meet the recommendations in the European Union? The results of a headcount*

\begin{tabular}{|c|c|c|c|c|c|c|}
\hline \multirow[b]{2}{*}{ Nutrient/food item } & \multirow[b]{2}{*}{ Criterion } & \multicolumn{5}{|c|}{$\begin{array}{l}\text { Number of countries meeting } \\
\text { the recommendation in (3-year average): }\end{array}$} \\
\hline & & $1961-1963$ & $1969-1971$ & $1979-1981$ & $1989-1991$ & 1999-2001 \\
\hline \multirow[t]{2}{*}{ Total protein } & $>30 \%$ & 0 & 1 & 1 & 1 & 1 \\
\hline & $<15 \%$ & 0 & 0 & 0 & 0 & 0 \\
\hline \multirow[t]{2}{*}{ Fat } & $>30 \%$ & 10 & 10 & 13 & 14 & 14 \\
\hline & $<15 \%$ & 0 & 0 & 0 & 0 & 0 \\
\hline Saturated fatty acids & $>10 \%$ & 9 & 10 & 11 & 13 & 12 \\
\hline \multirow[t]{2}{*}{ Polyunsaturated fatty acids } & $<6 \%$ & 12 & 12 & 7 & 6 & 5 \\
\hline & $>10 \%$ & 0 & 0 & 0 & 0 & 0 \\
\hline \multirow[t]{2}{*}{ Carbohydrates } & $<55 \%$ & 8 & 12 & 13 & 14 & 14 \\
\hline & $>75 \%$ & 0 & 0 & 0 & 0 & 0 \\
\hline Cholesterol & $>300$ mg person $^{-1}$ day $^{-1}$ & 10 & 10 & 13 & 14 & 14 \\
\hline Fruits and vegetables & $>400$ g person $^{-1}$ day $^{-1}$ & 6 & 9 & 9 & 12 & 14 \\
\hline Sugar & $>10 \%$ & 8 & 11 & 10 & 9 & 10 \\
\hline
\end{tabular}

${ }^{*}$ Maximum 14.

to 14 countries by 1999-2001. Likewise, the number of countries below the $6 \%$ limit for polyunsaturated fatty acids declined constantly from 12 to five. In tandem, however, the number of countries with national averages above the recommended $300 \mathrm{mg}$ cholesterol limit and the 30\% level for total fat increased from 10 to include all EU member countries. The following sections analyse in greater detail (1) which individual countries have shown improvements and deteriorations and (2) the degree of change.

\section{Changes in nutrient intakes by country}

Total energy availability

At the most general level, changes in dietary patterns are characterised by their levels of total dietary energy supply. Figures 2 and 3 show total availability of energy in individual EU countries in 1961 and 2001 divided into animal and vegetable sources. Most notable is that: (1) overall energy availability has risen from an average of $2984 \mathrm{kcalperson}^{-1} \mathrm{day}^{-1}$ in 1961 to $3505 \mathrm{kcal}$ person $^{-1}$ day $^{-1}$ in 2001, an increase of $17 \%$; (2) poorer countries at the beginning of the period, notably those from the Mediterranean region, have rapidly caught up with and often overtaken richer countries in terms of energy supplies; and (3) the share of animal products in the total has risen, again most notably among the (traditionally) poorer countries (e.g. in Spain from 13.5 to $30 \%)$

\section{Sugar consumption}

One of the most controversial recommendations is that energy from sugar should not exceed $10 \%$ of total dietary energy supplies. The basic case for this limit lies in the empirical observation that high shares of sugar in the diet are associated with adverse health outcomes, notably micronutrient deficiencies and tooth decay. These problems are particularly pronounced in developing countries. Moreover, the high energy density of sugar is a contributing factor to overweight and obesity in all countries.

As far as the EU as a whole is concerned, the last 40 years have seen a number of changes in the importance of sugar in the overall diet across member countries. In 1961, the proportion of energy from sugar varied considerably (Fig. 4). It was considerably below the $10 \%$ mark in the Mediterranean countries as well as Belgium and France, while it was substantially above that mark in the UK, Ireland, Denmark and Sweden. Over the next 40 years, sugar energy shares began to converge and all countries came closer to the 10\% level (Fig. 5). The rising and declining shares have - by and large - offset each other over time and the average for the EU as a whole has remained largely unchanged at around $11 \%$.

\section{Lipids and their fatty acid structure}

The empirical findings for total lipid consumption patterns across countries (not shown for the sake of brevity) suggest that the changes in total lipid intake are characterised by the same convergence process that characterised sugar consumption. Unlike sugar, however, lipid consumption levels converged at a higher average level, up from 31\% in 1961 to nearly 38\% in 2001. Again the convergence is the result of diverging developments in individual countries. The Mediterranean countries start off from a healthy level and gradually catch up with the other countries, which experience more moderate increases in the share of lipids in their diets.

It should be recalled, however, that fats and oils (lipids) are also the commodity group where the difference between 'apparent' energy consumption and actual intake is highest. This is particularly the case where fats and oils, used for frying food, are thrown away rather than eaten. In these cases, a part of the increase in dietary energy supply may be a reflection of increased waste rather than increased consumption. 


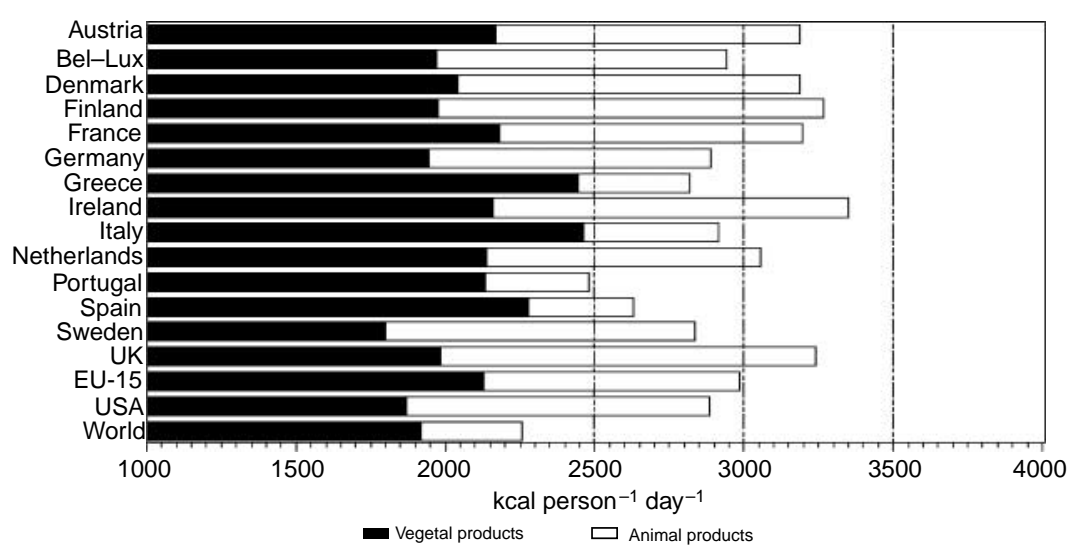

Fig. 2 Shares of energy from animal and vegetal products, 1961. Source: Food and Agriculture Organization's FAOSTAT database (2003)

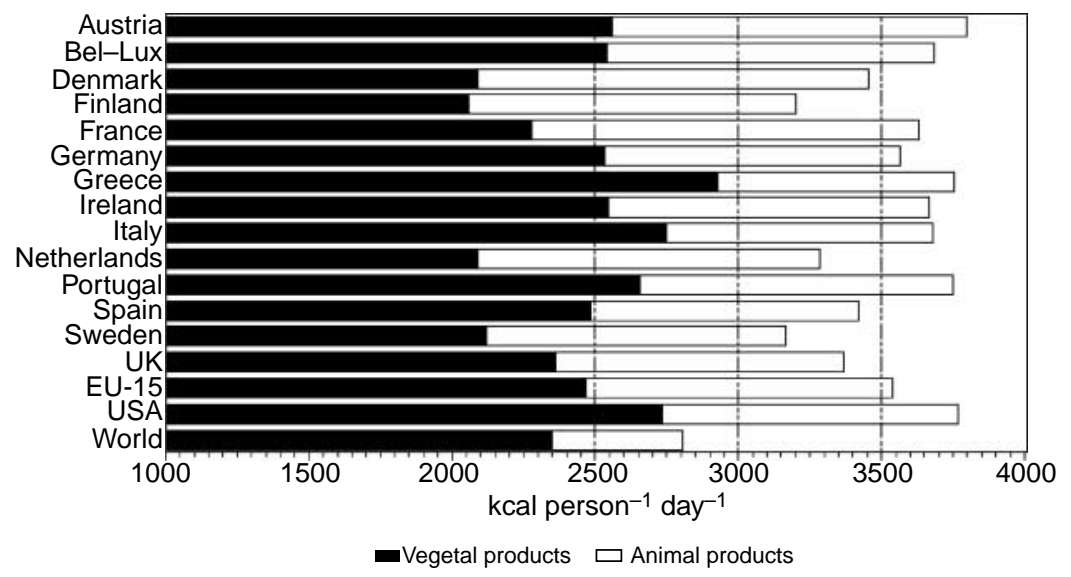

Fig. 3 Shares of energy from animal and vegetal products, 2001. Source: Food and Agriculture Organization's FAOSTAT database (2003)

From a health perspective, the fatty acid composition of the diet is as important as its total lipid content. While saturated fatty acids and trans fatty acids are associated with adverse health impacts, polyunsaturated fats in general and omega-3 fatty acids in particular have been found to promote good health and longevity. The WHO/FAO consultation made recommendations for total, saturated and polyunsaturated fatty acids and for monounsaturated as a residual (implicitly, from Table 1, 0-24\%)*.

It is therefore not surprising to see that the Mediterranean countries had, in 1961, when they followed more closely a Mediterranean diet with low consumption of meat, butter and eggs, managed to maintain fairly low consumption levels of saturated fatty acids. However, as these countries integrated into the EU, their dietary patterns also converged towards those of core EU countries (Figs 6 and 7). The comparison also shows that those countries that had excessively

*They also made a recommendation for omega-3 fatty acids of $1-2 \%$, but we do not have information in our nutrient database to examine this component. high consumption levels of saturated fatty acids $(>15 \%)$ like Finland or Ireland managed to reduce them to close to the recommended maximum. Again, as for the overall energy availability at country level and sugar availability, the process over the past 40 years was one of convergence where excessively low and high intake levels gradually disappeared. This nutrient convergence across countries also holds for intake levels of cholesterol, which is highly correlated with saturated fatty acid levels and therefore not shown separately.

Notwithstanding this convergence process and notwithstanding the fact that the recommended maxima for cholesterol and saturated fats have been exceeded in most Mediterranean countries, Spain, Portugal, Italy and Greece still remain at the lower end of the EU country spectrum. In general, it seems that the lipid intake in these countries continues to be of a better nutritional quality than in countries like Austria, Finland or Ireland. This is further demonstrated with respect to monounsaturated fatty acids (not shown for reasons of space and because no countries lie outside the very wide implicit WHO/FAO recommendation of $0-24 \%$ share of energy). Spain, Greece and Portugal have the highest levels in the 


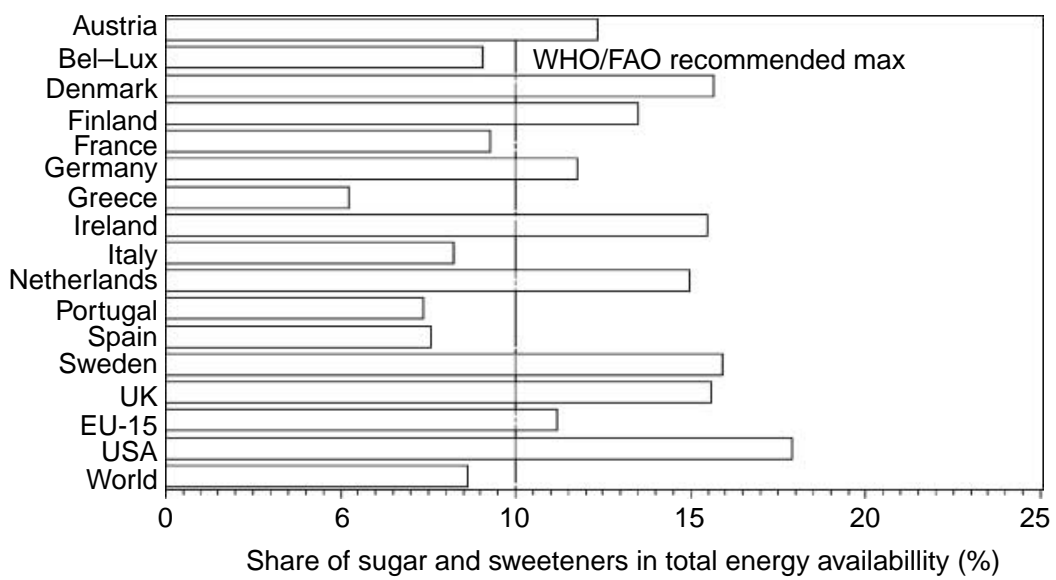

Fig. 4 Share of energy from free sugars versus World Health Organization (WHO)/Food and Agriculture Organization (FAO) recommendations, 1961. Source: FAO's FAOSTAT database (2003)

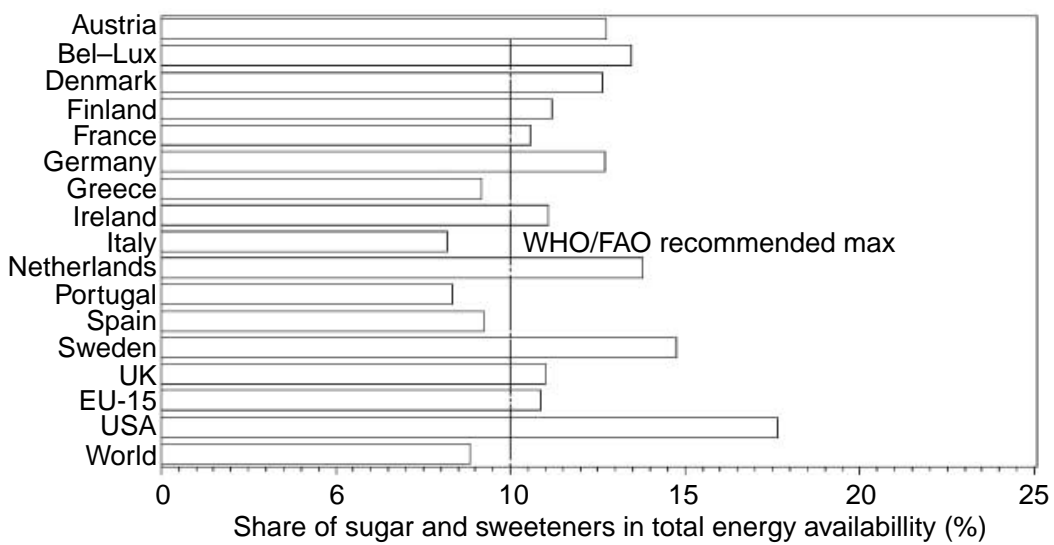

Fig. 5 Share of energy from free sugars versus World Health Organization (WHO)/Food and Agriculture Organization (FAO) recommendations, 2001. Source: FAO's FAOSTAT database (2003)

EU with more than $15 \%$ of their calories from this source*. For polyunsaturated fatty acids (Figs 8 and 9) only Denmark and The Netherlands reached the minimum 6\% target in 1961; by 2001 Denmark had dropped below 6\%. All other countries but Finland and France are now in the recommended range.

\section{Fruit and vegetables}

High levels of fruit and vegetable consumption are generally associated with positive health effects, even though the benefits of high consumption levels cannot easily be ascribed to a single nutrient or bioactive substance. In general, fruit and vegetables are rich in minerals, vitamins, fibre and antioxidants, and thus afford every diet with a host of essential nutrients. The broad spectrum of essential nutrients was the main reason for the explicit inclusion of fruit and vegetables into the

*The UK Food Standards Agency recently held a consultation and has recommended further research into the question of whether there is an optimal intake of monounsaturated fatty acids. dietary recommendations*. This broad range of benefits also explains why fruit and vegetable consumption has been targeted for increase by most countries in campaigns to promote healthy eating (e.g. the 5-a-day campaign).

FBS data suggest that all EU countries have reached and exceeded the recommended minimum intake levels for fruit and vegetables. This marks an important enhancement in the evolution of dietary patterns: 40 years ago only six countries had more than $400 \mathrm{~g}$ of fruit and vegetables available per person per day (Fig. 10). These improvements notwithstanding, 'apparent' consumption of fruit and vegetables may overstate, more than for any other product category, actual intake levels (Fig. 1). For example, intake data for the $\mathrm{UK}^{16}$ suggest that average fruit and vegetable consumption among 19- to 64-year-olds is below three $80 \mathrm{~g}$ portions per day, i.e. below $240 \mathrm{~g}$, whereas FBS availability estimates are significantly in excess of $400 \mathrm{~g}$. This suggests that losses

*Note that the WHO/FAO recommendation for fruit and vegetables is in terms of aggregate weight (in grams) rather than in terms of energy or other nutrient share in the diet. 


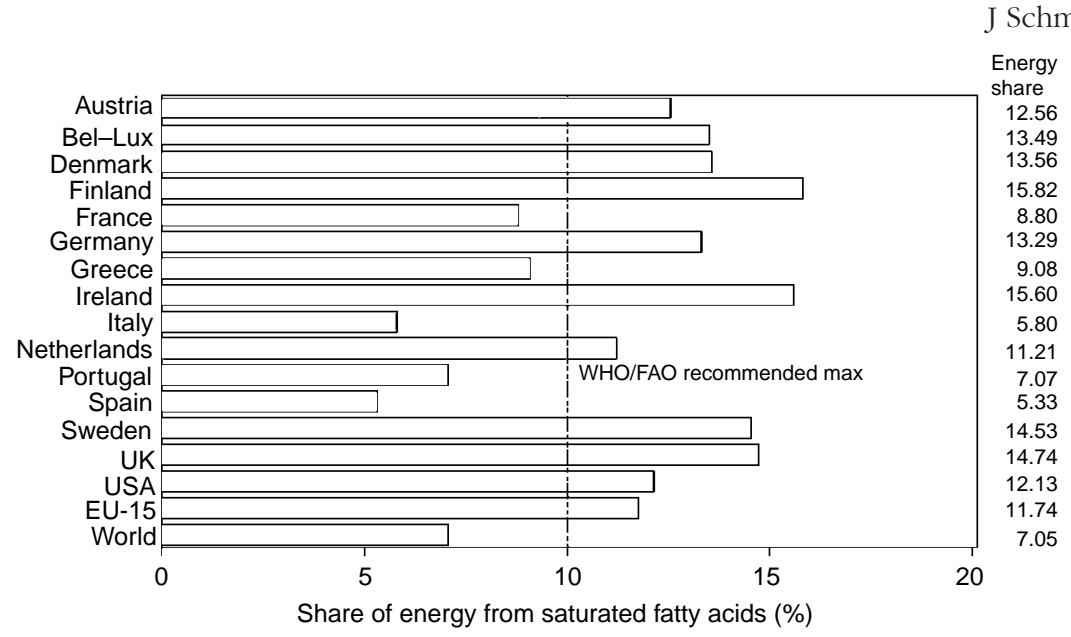

Fig. 6 Share of energy from saturated fatty acids versus World Health Organization (WHO)/Food and Agriculture Organization (FAO) recommendations, 1961. Source: Josef Schmidhuber, Global Perspectives Studies Group, FAO (2003)

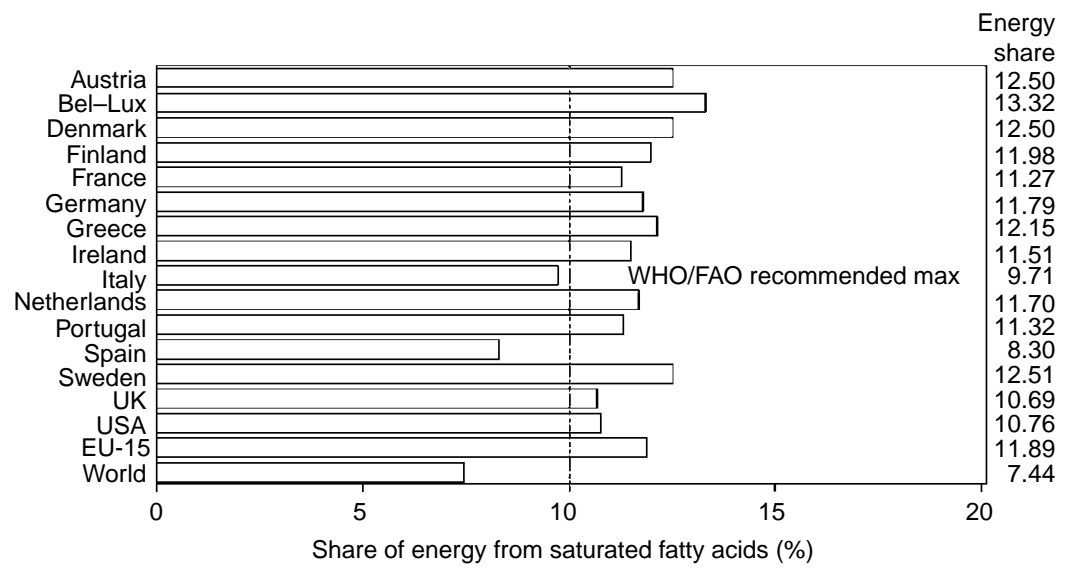

Fig. 7 Share of energy from saturated fatty acids versus World Health Organization (WHO)/Food and Agriculture Organization (FAO) recommendations, 2001. Source: Josef Schmidhuber, Global Perspectives Studies Group, FAO (2003)

could account for more than $40 \%$ of availability at country level. Likewise, using DAFNE data, Naska et al. ${ }^{17}$ found that only in the Mediterranean countries did the mean daily population intake of fruit and vegetables clearly exceed recommendations.

Notwithstanding these high potential losses for fruit and vegetables, there has been an impressive increase in overall availability, and in most countries the recommendation has been exceeded by a considerable margin of sometimes more than 100\%. This means that, even after accounting for high losses, most country averages would still be above the recommendation of 400 g person $^{-1}$ day $^{-1}$ (Fig. 11). What is more, there are reasons to believe that the variety of fruits and vegetables available to consumers has increased and their availability throughout the year has improved.

\section{In summary}

Europeans on average eat enough of everything, probably too much overall and certainly too much sugar and lipids, particularly saturated fat and cholesterol. Particularly the saturated fat and cholesterol content has increased over the past 40 years. In tandem, there has also been an enhancement in diets, particularly through higher fruit and vegetable consumption but also lower shares of energy from free sugars. Ironically, the driving forces for both enhancements and deteriorations appear to be the same or similar across the different countries. Trade and overall economic integration, urbanisation, improved infrastructure and the growing dominance of supermarkets have played an important role. So too have a general rise in living standards and decreases in the real price of food. All in all, diets of European countries have become more similar over time. This convergence process will be described and quantified in the following section.

\section{Patterns of change in overall dietary similarity}

The preceding section described changes in consumption patterns for individual nutrients. A common theme throughout the analysis was that the consumption levels for these nutrients in individual countries have become 


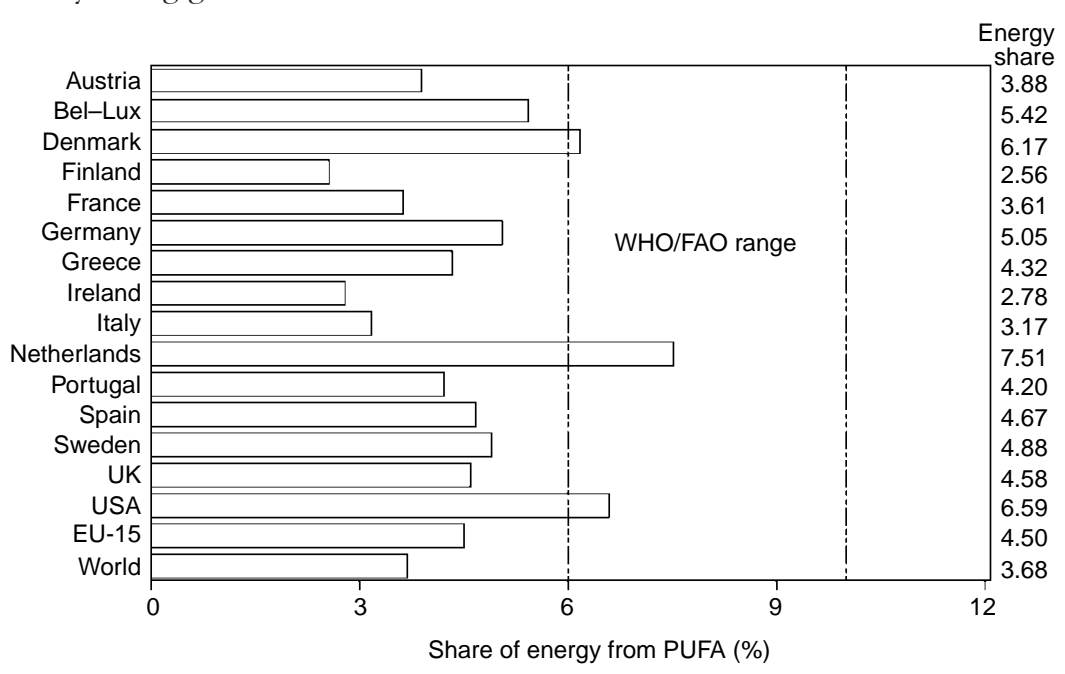

Fig. 8 Share of energy from polyunsaturated fatty acids (PUFA) versus World Health Organization (WHO)/Food and Agriculture Organization (FAO) recommendations, 1961. Source: Josef Schmidhuber, Global Perspectives Studies Group, FAO (2003)

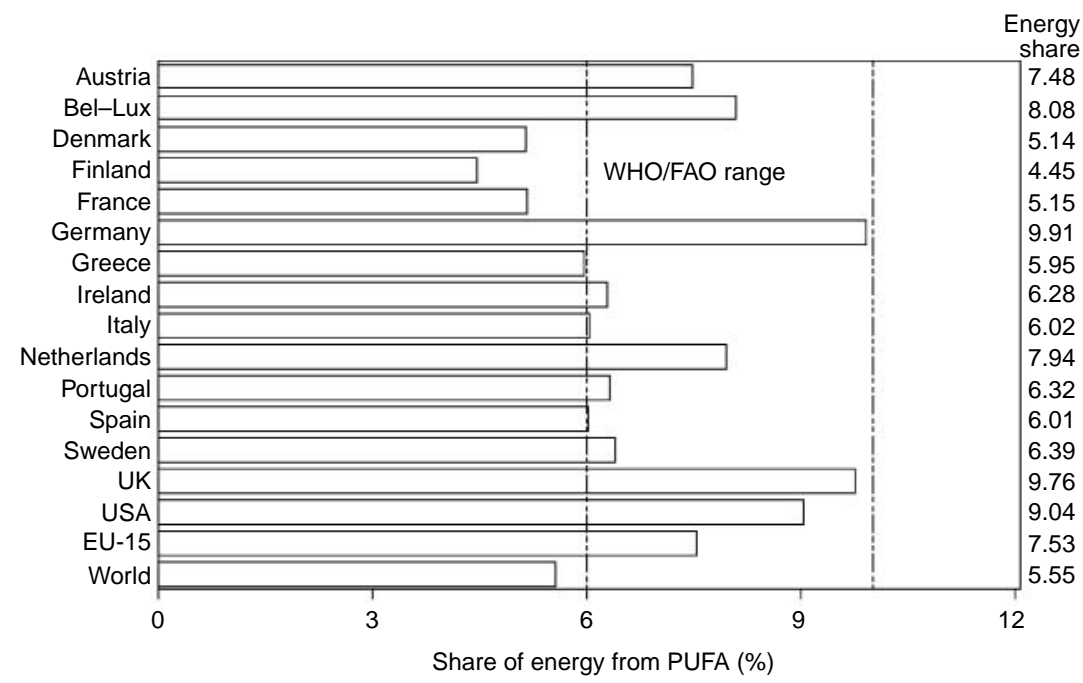

Fig. 9 Share of energy from polyunsaturated fatty acids (PUFA) versus World Health Organization (WHO)/Food Agriculture Organization (FAO) recommendations, 2001. Source: Josef Schmidhuber, Global Perspectives Studies Group, FAO (2003)

more similar over time. The next question that arises from this finding is whether the results from a few individual nutrients can be extended to the entire diet.

\section{Quantifying similarity and convergence of consumption patterns}

To examine the question of similarity and convergence (more similarity over time), we propose and then apply a measure for the similarity of food consumption patterns. We refer to this measure as the consumption similarity index (CSI), which we define as:

$$
C S I_{j, k}=1-\frac{1}{2}\left(\sum_{i=1}^{426}\left|\frac{\operatorname{Cal}_{i j}}{\operatorname{Cal}_{j}}-\frac{\mathrm{Cal}_{i k}}{\mathrm{Cal}_{k}}\right|\right),
$$

where $i=1$ to 426 food items of FAO's SUA database; Cal $_{i j}$ and $\mathrm{Cal}_{i k}$ are the energy from individual products $i$ in countries $k$ and $j$; and $C a l_{j}$ and $C a l_{k}$ is the total energy availability per person in country $j$ and $k$.

The CSI* can vary, in per cent, from 0 to 100. A value of 60 , for instance, denotes that $60 \%$ of the energy in country $k$ comes from the same food sources as in country $j$. The CSI thus represents an aggregate measure for the overlap of food consumption patterns in two different countries - based on the energy content in the various food items consumed in the two countriest.

*The proposed CSI is one of a number of similarity indices. The measure used here, based on the intra-industry trade measure originally proposed by Michaely ${ }^{18}$, has not previously been used to measure similarity in diets. The method has the advantages of being familiar to many and easy to interpret.

†Space constrains us from looking at similarity with respect to other dimensions of food consumption such as lipid or sugar intake. 


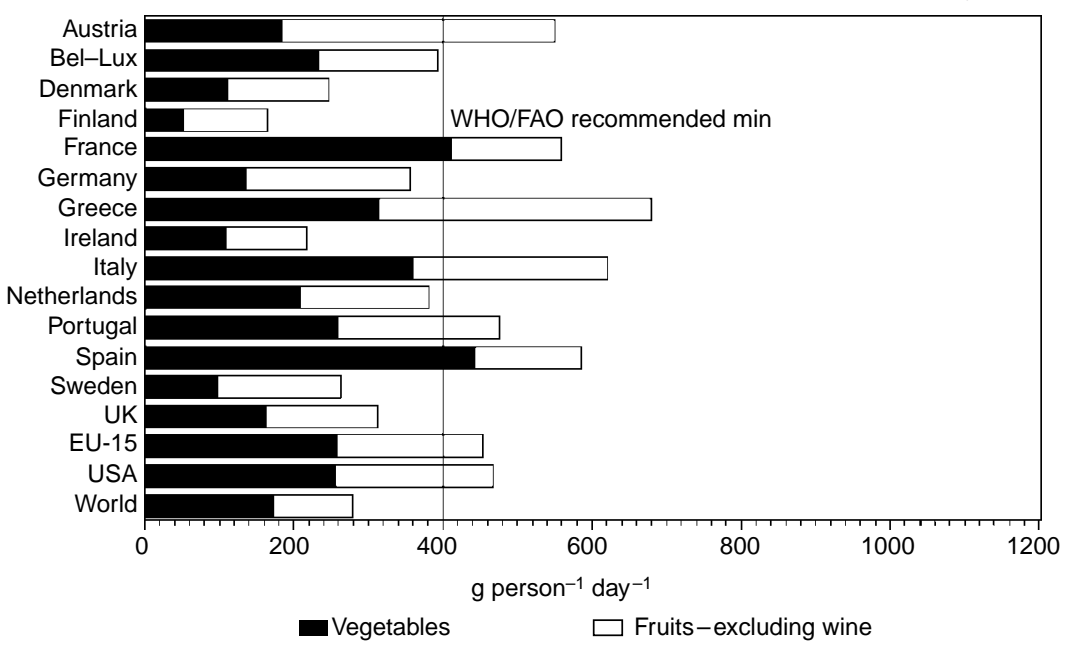

Fig. 10 Fruit and vegetable availability versus World Health Organization (WHO)/Food and Agriculture Organization (FAO) recommendations, 1961. Source: FAO's FAOSTAT database (2003)

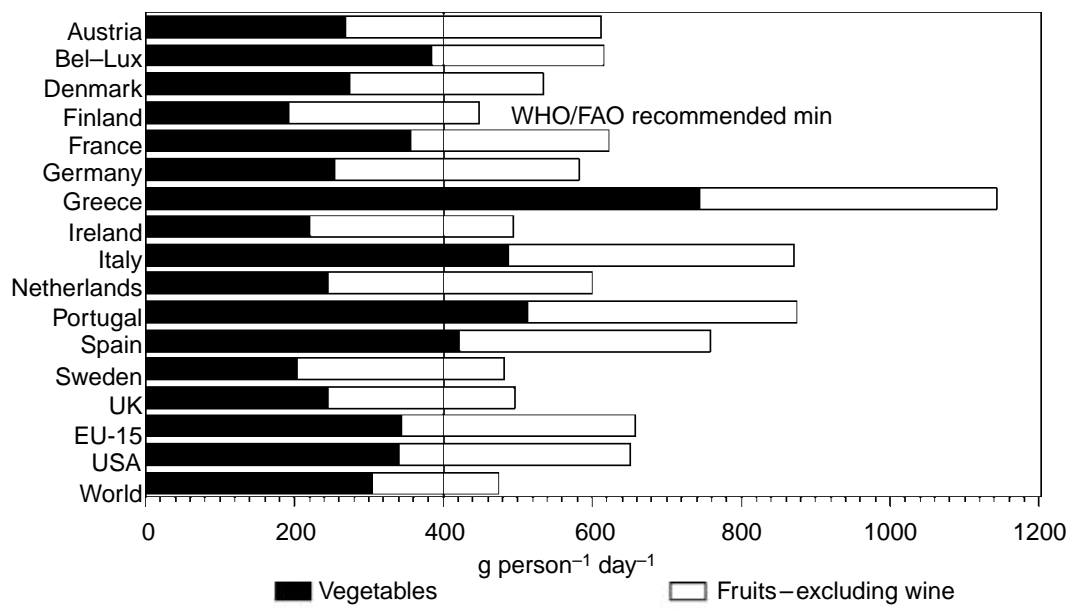

Fig. 11 Fruit and vegetable availability versus World Health Organization (WHO)/Food and Agriculture Organization (FAO) recommendations, 2001. Source: FAO's FAOSTAT database (2003)

\section{The empirical findings}

The calculations have been undertaken at the lowest possible level of aggregation ( 426 food items) and for all individual EU countries and three different comparator regions/countries: the USA, the EU and the world as a whole. The results of these calculations are summarised in Table 3. For the sake of space, only the 3-year averages of 1961-1963 and 1999-2001 are presented.

A first, uncontroversial insight is that consumption patterns between the USA and the EU are considerably more similar than between these countries and the world average. This was the case 40 years ago and is still the case. For the USA and the EU the increase in the CSI with the world average increased, from 51 to $53 \%$ and 56 to $59 \%$, respectively. There is no shortage of reasons to explain the relatively low overall overlap in consumption patterns between the world average and the chosen developed countries. Most importantly, the world average is dominated by developing countries' food consumption patterns, which are determined by different cultural habits and religious customs as much as by largely different income levels and development stages.

Obviously and intuitively, EU countries' diets are and have been more similar to the EU average than to the US diet. Within the EU, the similarity of consumption patterns has generally increased, the most pronounced increases are found for the Mediterranean countries acceding late to the EU, i.e. Greece, Portugal and Spain, where CSI values (compared with the EU average) increased from 54 to $66 \%$, 61 to $77 \%$ and 67 to $73 \%$, respectively. However, Table 3 illustrates further details of convergence. In the early 1960 s, for instance, diets in some EU countries were more similar to those in the USA than to each other or to the EU average. This is no longer the case and, in fact, the EU average and the USA are less similar now than they were in the early 1960s. The similarity of the diet between Denmark and Greece, for instance, nearly doubled over the last 40 years. 
ำ 守尔守 ம்

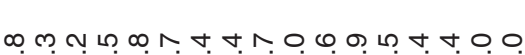
तरำ

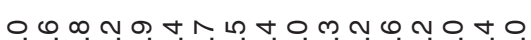

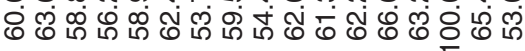

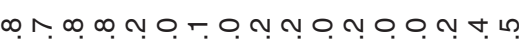

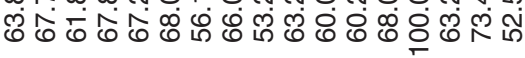

m n

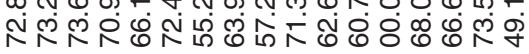

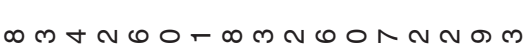

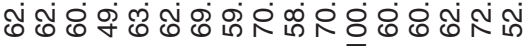

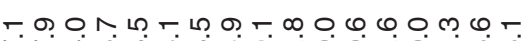
ธิ

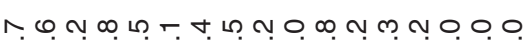

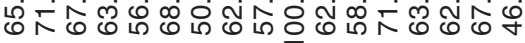

o

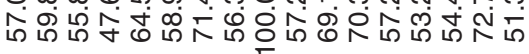

大

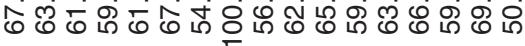

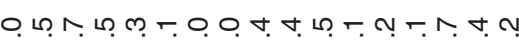

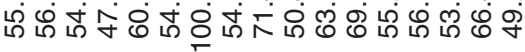

N.

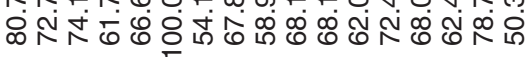

人

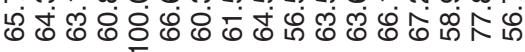

๑ ภู่

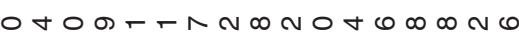

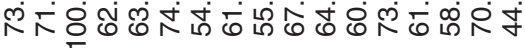

no.

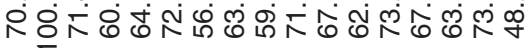

on nounotot ठำ 突 
Table 3 also reveals that geographic proximity has traditionally been a crucial determinant of similarity in food consumption patterns. It shows high similarities of food consumption patterns between geographic neighbours like Germany and Austria, Spain and Portugal or Ireland and the UK, very intuitive outcomes. Likewise, Table 3 underscores the impact of geographic distance, in the form of low CSI values, for Greece. Over time, however, the importance of geographic proximity in explaining similarities in consumption patterns has declined. The influence of distance has been fading as trade barriers and transportation costs have declined and overall economic integration has proceeded.

In summary, the CSI analysis confirms a growing similarity of food consumption patterns across EU countries. Not only have EU diets become more homogeneous, they have also become more clearly and increasingly differentiable from the dietary patterns outside the EU.

\section{Summary and conclusions}

The thrust of our paper has been that, over a 40-year period, there have been quite dramatic changes in EU diets. At the level of macronutrients, convergence has been the most notable tendency, with Mediterranean countries increasing their intake of free sugars, saturated fats and cholesterol, while the highest-intake Northern European countries moderated their consumption of these nutrients.

We have analysed the nutritional composition of diets in the EU and compared them with the recommendations that have emerged from a WHO/FAO consultation process. All in all, they suggest a considerable increase in the dietary energy supply over the past 40 years for the EU as a whole and a particularly rapid catch-up process for many Mediterranean countries. As regards the latter group, much of the traditional notion of a healthy Mediterranean diet appears to be at odds with actual food consumption patterns, particularly in Spain and Portugal. In addition to higher energy supply levels, there has been a shift in the composition of the diet. Nearly all country averages are above the recommended levels for cholesterol, saturated fats and sugar. The main positive development was a marked increase in the consumption of fruit and vegetables, but it was also found that FAO availability data may overstate this achievement more than for any other product group. Also significant, and noteworthy for policy-makers, is that diets can get better as well as worse, as evidenced by the improvements in some of the Northern European countries.

Although the data used in this paper have many weaknesses and the methods used are far from revolutionary, we believe that our analysis is a start in providing the types of information badly needed by policy-makers. It is, however, probable that advances in the nutritional sciences will make ever greater demands on policy-makers to influence their populations, or groups within their populations, to adopt healthier lifestyles including diets. They will also need to collect or have access to better data linking culture, values, attitudes and lifestyles to actual consumption, including the consumption of processed foods and foods consumed outside the household.

\section{Acknowledgement}

The authors acknowledge the helpful comments of three anonymous referees.

\section{References}

1 World Health Organization (WHO)/Food and Agriculture Organization (FAO). Diet, Nutrition and The Prevention of Chronic Diseases. Report of a Joint WHO/FAO Expert Consultation. WHO Technical Report Series No. 916. Geneva: WHO, 2003.

2 International Obesity Task Force (IOTF)/European Association for the Study of Obesity (EASO). www.iotf.org/ database/GlobalAdultAugust2005.asp.

3 Kenkel DS, Manning W. Economic evaluation of nutrition policy. Or there's no such thing as a free lunch. Food Policy 1999; 24(2-3): 145-62.

4 US Department of Agriculture, Economic Research Service. Food Borne Illness Calculator [online]. Available at http:// www.ers.usda.gov/data/foodborneillness/. Accessed 1 April 2004.

5 Grigg D. The European diet: regional variations in food consumption in the 1980s. Geoforum 1993; 24(3): 279-89.

6 Gil JM, Gracia A, Perez y Perez L. Food consumption and economic development in the European Union. European Review of Agricultural Economics 1995; 22(3): 385-99.

7 Tiffin R, Tiffin A. Estimates of food demand elasticities for Great Britain. Journal of Agricultural Economics 1999; 50(1): $140-7$.

8 Mazzocchi M. Time-varying parameters in the Almost Ideal Demand System: an empirical appraisal. European Review of Agricultural Economics 2003; 30(2): 241-70.

9 Lusk JL, House LO, Valli C, Jaeger SR, Moore M, Morrow JL, et al. Effect of information about benefits of biotechnology on consumer acceptance of genetically modified food: evidence from the United States, England and France. European Review of Agricultural Economics 2004; 31(2): 179-204.

10 Huang KS. Nutrient demand elasticities in a complete food demand system. American Journal of Agricultural Economics 1996; 78: 21-9.

11 Chen S-H, Shogren JF, Orazem PF, Crocker TD. Prices and health: identifying the effects of nutrition, exercise and medication choices on blood pressure. American Journal of Agricultural Economics 2002; 84: 990-1002.

12 Lagiou P, Trichopoulou A. The DAFNE Initiative: the methodology for assessing dietary patterns across Europe using household budget survey data. Public Health Nutrition 2001; 4(6): 1135-41.

13 US Department of Agriculture. National Nutrient Database for Standard Reference, Release 16 [online]. Available at http://www.nal.usda.gov/fnic/foodcomp/Data/SR16/ sr16.html. Accessed 1 April 2003.

14 Putnam J, Allshouse J, Kantor LS. Per capita food supply trends: more calories, refined carbohydrates and fats. FoodReview 2002; 25(3): 2-15. 
15 Kantor LS, Lipton K, Manchester A, Oliveira V. Estimating and addressing America's food losses. FoodReview 1997: (Jan-Apr): 2-12.

16 Henderson L, Gregory J, Swan G. National Diet and Nutritional Survey. London: HMSO, 2002.

17 Naska A, Vasdekis VGS, Trichopoulou A, Friel S, Leonhauser IU, Moreiras O, et al. Fruit and vegetable availability among ten European countries: how does it compare with the 'five-a day' recommendation? DAFNE I and II projects of the European Commission. British Journal of Nutrition 2000; 84(4): 549-56.

18 Michaely M. Multilateral balancing in international trade. American Economic Review 1962; LII. 